\title{
Rootstock Effects on Deficit-Irrigated Winegrapes in a Dry Climate: Grape and Wine Composition
}

\author{
James F. Harbertson ${ }^{1 *}$ and Markus Keller ${ }^{2}$
}

\begin{abstract}
This study compared own-rooted vines and different scion/rootstock combinations in arid eastern Washington, where vineyards are primarily deficit-irrigated and own-rooted. The performance of Chardonnay, Merlot, and Syrah on five rootstocks (5C, 140Ru, 1103P, 3309C, and 101CU) or on their own roots was evaluated with 10 field replicates over three vintages (2007-2009) in the Yakima Valley AVA. At harvest, two field replicates each were combined to make five winemaking replicates; $45 \mathrm{~kg}$ of grapes were made into wine. The grape variables measured were total soluble solids (TSS), titratable acidity (TA), $\mathrm{pH}$, potassium (skin, seeds and pulp), tannins (skin and seeds), and anthocyanins. Wine variables measured were ethanol, TA, $\mathrm{pH}$, potassium, tannins, total iron reactive phenolics, anthocyanins, and polymeric pigments. Rootstock caused few significant differences in fruit and wine composition and instead the dominant factors were scion and, to a lesser extent, vintage. All fruit and wine variables measured with the exception of TSS varied significantly with scion. Only TSS and berry size were consistently affected by vintage. Rootstock had no effect on grape anthocyanins and tannins. However, significant but small and variable effects were observed for wine anthocyanins and tannins. Wines from own-rooted vines tended to have somewhat higher $\mathrm{pH}$, potassium, and total tannin than did wines from grafted vines. The relationships between fruit and wine for anthocyanins and tannins were not straightforward and warrant further research.
\end{abstract}

Key words: rootstock, wine, grape, scion, tannins, anthocyanins, polymeric pigments, potassium, Merlot, Syrah, Chardonnay, Vitis vinifera

The world's major winegrape (Vitis vinifera L.) cultivars are susceptible to damage and decline by the root louse phylloxera (Daktulosphaira vitifoliae Fitch) and various species of nematodes, and thus they are typically grafted to crosses of North American Vitis species, which have resistance or tolerance to these pests. Certain rootstocks are also utilized to adapt to adverse soil conditions such as salinity, $\mathrm{pH}$ (alkaline and acidic), and extremes in water availability (drought and flooding). The genotype of the scion is thought to determine the types of compounds synthesized in the fruit (Gholami et al. 1995), while rootstocks are thought to have an indirect effect on fruit composition by primarily influencing the vegetative growth of the grafted wine, including vine vigor, canopy size, and fruit yield (e.g., Keller 2010).

Few studies have been conducted to evaluate the effect of rootstock on wine composition because of the necessary additional experimental design and logistical requirements.

\footnotetext{
${ }^{1}$ Associate Professor of Enology, School of Food Science, and ${ }^{2}$ Professor of Viticulture, Department of Horticulture and Landscape Architecture, Washington State University, Irrigated Agriculture Research and Extension Center, 24106 N. Bunn Rd., Prosser, WA 99350.

*Corresponding author (email: jfharbertson@wsu.edu; fax: 509 786-9370)

Acknowledgments: The authors acknowledge the Northwest Center for Small Fruits Research for their support of this project.

S. Spayd and R. Wample are thanked for initial project development as well as L. Mills, S. Wran, M. Mireles, E. Harwood, G. Gasic, C. Beaver, and L.F. Casassa for technical assistance with the project.

Supplemental data is freely available with the online version of this article at www.ajevonline.org.

Manuscript submitted Aug 2011, revised Oct 2011, accepted Oct 2011

Copyright $(\underset{2}{ } 2012$ by the American Society for Enology and Viticulture. All rights reserved.

doi: 10.5344/ajev.2011.11079
}

Another limitation is the lack of own-rooted vines as a control. Of the experiments that include own-rooted vines, all have been conducted in Australia (Walker et al. 1998, 2000, 2010, Gong et al. 2010), with the majority focusing on scion $\times$ rootstock interactions with irrigation water salinity (Walker et al. 2000, 2010, Gong et al. 2010). In studies where experiments have been conducted on fruit with winemaking, only primary grape and wine components have been evaluated (total soluble solids, $\mathrm{pH}$, titratable acids: tartaric and malic acid, anthocyanins, total phenolics, and potassium) and none have measured tannins or volatile aroma compounds from fruit or wine. Very few scion/rootstock combinations have been evaluated in any given trial, and most of the work has been with Shiraz and Chardonnay grafted to Ramsey, although some other cultivars (Muscat of Alexandria, Cabernet Sauvignon) and rootstocks (1103P, 140Ru, K51-40, Schwarzmann, Rupestris St. George, 1202 Couderc, and 101-14 Mgt) have been evaluated (Walker et al. 1998, 2000, 2010, Gong et al. 2010). Only one of the field trials combined with winemaking was for more than one year (Walker et al. 2010), and not all scion/rootstock combinations were made into wine. Thus, the impact of rootstock and scion/rootstock combination on wine composition has not been evaluated over several vintages to determine if there are consistent effects.

One of the most consistent observations found in multiple studies was that potassium was typically significantly higher in wines made from grafted vines (Ramsey, 1103P, 140Ru, 101-14 Mgt) using both red (Shiraz, Cabernet Sauvignon) and white (Chardonnay, Muscat of Alexandria, Riesling) grape varieties (Walker et al. 1998, 2000). This observation was linked to site salinity, with low salinity sites having greater amounts of potassium present in wines made from grafted 
vines (Walker et al. 2000). Own-rooted Cabernet Sauvignon had significantly greater total anthocyanins and total phenolics than wines made from vines grafted to Ramsey, but that was not true for Shiraz (Walker et al. 1998). This result was later confirmed (Walker et al. 2000), with the finding that Shiraz wines made from grapes grafted to several rootstocks (Ramsey, 1103P, 140Ru, 101-14 Mgt) and an own-rooted control had similar total anthocyanin concentrations.

Because phylloxera has been cited as the cause of some of the largest losses to winegrapes in European and American history, research was begun in Washington State in 1999 to evaluate the impact of rootstock on vine performance and fruit and wine composition. To date vineyards in Washington are primarily own-rooted, so an own-rooted treatment was included in the experiment. A key additional environmental factor in eastern Washington is its arid climate due to the limited annual rainfall $(152-254 \mathrm{~mm})$. To this end, the rootstocks $V$. berlandieri $\times V$. riparia Teleki 5C (5C), $V$. berlandieri $\times V$. rupestris 140 Ruggeri (140Ru), 1103 Paulsen (1103P), and $V$. riparia $\times V$. rupestris 3309 Couderc (3309C) were grafted to the three $V$. vinifera cultivars Chardonnay $(\mathrm{CH})$, Merlot (MR), and Syrah (SY) and evaluated under reduced water conditions. Also included was an unnamed rootstock from Cornell University, which is likely a sibling or seedling of 101-14 Mgt and has been denoted here as $101 \mathrm{CU}$. The goal here is to report on the influence of rootstock on grape and wine composition over three consecutive vintages. Comparing the influence of rootstocks on various scions over multiple years is important to test whether any perceived rootstock effect is consistent, or stable, across scions and over time. A companion study was conducted to evaluate the influence of grafting and rootstock cultivar, and their interactions with different scions, on scion growth, yield formation, and fruit ripening under conditions of deficit irrigation (Keller et al. 2012).

\section{Materials and Methods}

Vineyard. Chardonnay, Merlot, and Syrah were each grafted to five different rootstocks (5C, 140Ru, 1103P, 3309C, and $101 \mathrm{CU}$ ) and also grown on their own roots (10 field replicates). The vineyard was planted in 1999 and field-grafted in 2002 and 2003. The vineyard was set up in two blocks with each cultivar represented in each block. Further information about the vineyard, including drip irrigation, pruning, and training, as well as details regarding the experimental design is provided in a companion paper (Keller et al. 2012). Grapes were hand-picked at $\sim 23$ to 24 Brix each year after being monitored biweekly beginning before veraison. Harvest dates for Chardonnay in 2007, 2008, and 2009 were 25 Sept, 1 Oct, and 22 Sept, respectively. For Merlot, harvest dates were 2 Oct, 14 Oct, and 29 Sept for the 2007, 2008, and 2009 vintages, respectively. Syrah was harvested on 11 Oct, 28 Oct, and 12 Oct for the 2007, 2008, and 2009 vintages, respectively.

Reagents. Bovine serum albumin (BSA, Fraction V powder), sodium dodecyl sulfate (SDS), triethanolamine (TEA), sodium chloride $(\mathrm{NaCl})$, ferric chloride hexahydrate, $(+)$-catechin, and chemicals used in buffer preparation were purchased from Sigma-Aldrich (St. Louis, MO).
White winemaking. Approximately $45 \mathrm{~kg}$ grapes were pressed for four cycles of $5 \mathrm{~min}$ at $0.5,1.0,1.5$, and $2.0 \mathrm{bar}$, respectively, using a Willmes Type 100 bladder press (Willmes, Lamperheim, Germany) or SK PSP 8 pneumatic press (SK Group, Ljubljana, Slovenia). The resulting juice was transferred to a variable-capacity $100 \mathrm{~L} 14$-gauge stainlesssteel tank (Ghidi, Buggiano, Italy). White wine fermentation was conducted in a walk-in temperature control room at $14^{\circ} \mathrm{C}$ using an inoculum of Red Star Premier Cuvee yeast (Davis 796) (Lesaffre Group, Maison-Alfort, France) at 240 $\mathrm{mg} / \mathrm{L}$ (inoculation day 3). On day 4, $366 \mathrm{mg} / \mathrm{L}$ diammonium phosphate was added, and on day $5,100 \mathrm{mg} / \mathrm{L}$ Superfood (Lesaffre, Milwaukee, WI) was added. Fermentations were monitored daily with an Anton Paar DMA 35n hand-held density meter (Anton Paar, Graz, Austria) and were deemed complete after the residual sugar as measured by the Rebelein method (Rebelein 1973) was $5 \mathrm{~g} / \mathrm{L}$ or less (data not shown). Wines were treated with bentonite at $0.96 \mathrm{~g} / \mathrm{L}$ after primary fermentation was complete, racked, and then stored in 18.9 $\mathrm{L}$ glass carboys at $11^{\circ} \mathrm{C}$ until bottling.

Red winemaking. $45 \mathrm{~kg}$ of fruit was crushed and destemmed into $120 \mathrm{~L}$ bins using a DD C0 10 crusher/destemmer (Macchine Enolgiche Agricole Alto Tevere, Città di Castello, Italy) and tipped into $300 \mathrm{~L}$ jacketed (glycol cooled) stainlesssteel tanks (Ghidi). Tank temperature was controlled using a TankNet web-based fermentation management system using a TP-1 temperature probe set to $26^{\circ} \mathrm{C}$ (Acrolon Technologies, Napa, CA). The must was inoculated with Red Star Pasteur Red yeast (Davis 904) (Lesaffre Group, Maison-Alfort, France) at $240 \mathrm{mg} / \mathrm{L}$ on day 2 . Punch downs were done manually three times a day for 5 min starting on day 2 until pressing on day 9 , with three cycles of $0.5,1.0$, and 2.0 bar using a SK PSP 8 pneumatic press. Press fractions were added back to the original lot. Malolactic fermentation was conducted simultaneously with the primary fermentation by inoculating with $10 \mathrm{mg} / \mathrm{L}$ SB3 lactic acid bacteria Oenococcus oeni (Laffort, Bordeaux, France) $48 \mathrm{hr}$ after yeast inoculation. Fermentations were monitored daily with an Anton Paar DMA 35n hand-held density meter and were deemed complete after the residual sugar as measured by the Rebelein method (Rebelein 1973) was $5 \mathrm{~g} / \mathrm{L}$ or less. Secondary fermentation was monitored using paper chromatography (Iland et al. 2004) and was deemed complete after the malic acid spot was no longer found.

Fruit and wine chemistry. At harvest, 250 berry samples were taken from each replicate and subsampled (50 berries) to measure total soluble solids (TSS) (Atago, Tokyo, Japan), $\mathrm{pH}$, and titratable acidity (TA) (DL50 Autotitrator, Mettler Toledo, Columbus, OH). 30-berry replicates were assessed for skin tannins and seed tannins (Harbertson et al. 2002) and 50-berry replicates were assessed for anthocyanins (Iland et al. 2004). In 2008 and 2009, potassium was assessed according to Harbertson and Harwood (2009). For each scion/rootstock combination, four randomly selected 30-berry replicates (skins, seed, and pulp) after dissection and 65\% nitric acid (w/w) $/ 35 \% \mathrm{H}_{2} \mathrm{O}_{2}(\mathrm{w} / \mathrm{v})$ digestion were taken from the original 10 replicates. Potassium was measured using a flame photometer (Jenway, Essex, England). Wines were 
assayed for alcohol concentration (using an electric ebulliometer; Dujardin-Salleron, Paris, France), pH and TA (Mettler Autotitrator $\mathrm{pH}$ meter), and potassium (flame photometer). Phenolics, including tannins, anthocyanins, polymeric pigments (small, SPP; large, LPP; total, TPP), and total iron reactive phenolics, were measured in a DU $640 \mathrm{UV} /$ vis spectrophotometer (Beckman, Brea, CA) at room temperature (Harbertson et al. 2002, 2003, Piccioto 2002, Heredia et al. 2006).

Experimental design. The rootstock vineyard project was designed to have 10 field replicates with 18 different scion/rootstock combinations $(3$ scion $\times 6$ rootstock cultivars) over three vintages (2007-2009). Two field replicates were combined for each scion/rootstock combination to give five winemaking replicates for a total of 90 wine lots per vintage. The original design was carried out, but the number of replicates varied from the original design because some vineyard replicates produced less fruit than required for wine production. In these cases, the fruit was combined with another low-yielding replicate and no less than three wine replicates were made for each scion/rootstock combination. Data analysis was performed using Statistica (Statsoft Tulsa, OK). For data analysis of fruit, a three-way factorial analysis of variance (ANOVA) was performed for vintage $(2007,2008$, 2009), rootstock (own-rooted, 101CU, 1103P, 3309C, 140Ru, $5 \mathrm{C})$, and scion (CH, MR, SY). For anthocyanins, a threeway factorial ANOVA was performed with the previously described categorical predictors except for the $\mathrm{CH}$ scion. For skin and seed tannins, fewer replicates per scion/rootstock combination were analyzed per year because of the tedious nature of the work $(n \geq 4)$. For fruit potassium only four field replicates from each scion/rootstock combination were evaluated for the 2008 and 2009 vintages. Each experimental replicate for each analysis represented the average of two analytical replicates. In cases where a significant vintage scion interaction was observed, a secondary two-way ANOVA was performed, selecting a single scion with rootstock and vintage as categorical predictors. Pairs of variables were evaluated using correlation analysis.

\section{Results}

Fruit. Rootstock effects on basic grape maturity parameters (TSS, TA, pH, berry weight) for all three scions (SY, $\mathrm{MR}, \mathrm{CH}$ ) were determined (Table 1). Only $\mathrm{pH}$ showed a significant rootstock effect. Fruit from own-rooted vines tended to have higher $\mathrm{pH}$ than fruit from grafted vines. However, while fruit from own-rooted $\mathrm{CH}$ and MR had significantly higher $\mathrm{pH}$ than the other rootstocks, fruit from own-rooted SY was only significantly higher than 3309C. Between scions there were no significant impacts on TSS; however, for $\mathrm{pH}$, TA, and berry weight, there were some observed differences. $\mathrm{SY}$ and $\mathrm{CH}$ had significantly higher TA than MR, while MR and SY had significantly higher $\mathrm{pH}$ than $\mathrm{CH}$. SY also had a significantly higher berry weight than $\mathrm{CH}$ and MR. For TSS, $\mathrm{pH}, \mathrm{TA}$, and berry weight, a significant vintage effect was observed.

A significant vintage $\times$ scion interaction was observed for each of the basic grape maturity parameters (Table 1). The trend for TSS was 2007>2009>2008, with exception of $\mathrm{CH}$ where 2007 was higher than 2008 and 2009. For pH, each scion cultivar showed some vintage differences but each with a different trend (MR: 2007<2009 $\leq 2008$, SY: $2008>2009 \geq 2007$, CH: $2007>2009 \geq 2008$ ). For TA, each scion had a different trend but in all cases each vintage differed significantly from the others (see Supplemental Table 1).

Table 1 Effect of rootstock on soluble solids (SS), titratable acidity (TA), pH, and berry weight at harvest on Chardonnay, Merlot, and Syrah over three vintages (2007-2009). Means are presented with standard error.

\begin{tabular}{|c|c|c|c|c|}
\hline & $\begin{array}{c}\text { SS } \\
\text { (Brix) }\end{array}$ & $\begin{array}{c}\text { TA } \\
\text { (g/L) }\end{array}$ & $\mathrm{pH}$ & $\begin{array}{c}\text { Berry wt } \\
\text { (g) }\end{array}$ \\
\hline \multicolumn{5}{|l|}{ Rootstock } \\
\hline Own-rooted & $24.1 \pm 0.2$ & $7.60 \pm 0.17$ & $3.54 \pm 0.01 \mathrm{a}^{\mathrm{b}}$ & $1.04 \pm 0.03$ \\
\hline $5 \mathrm{C}$ & $23.8 \pm 0.2$ & $7.70 \pm 0.15$ & $3.49 \pm 0.01 \mathrm{ab}$ & $1.05 \pm 0.02$ \\
\hline 140Ru & $23.9 \pm 0.3$ & $8.01 \pm 0.13$ & $3.45 \pm 0.02 b$ & $1.10 \pm 0.03$ \\
\hline $1103 P$ & $24.0 \pm 0.2$ & $7.70 \pm 0.13$ & $3.46 \pm 0.05 b$ & $1.05 \pm 0.02$ \\
\hline $3309 \mathrm{C}$ & $23.6 \pm 0.2$ & $7.80 \pm 0.12$ & $3.46 \pm 0.01 b$ & $1.13 \pm 0.03$ \\
\hline $101 \mathrm{CU}$ & $23.9 \pm 0.2$ & $7.65 \pm 0.13$ & $3.50 \pm 0.02 a b$ & $1.07 \pm 0.03$ \\
\hline \multicolumn{5}{|l|}{ Scion } \\
\hline Syrah & $23.9 \pm 0.2$ & $7.90 \pm 0.08 b$ & $3.53 \pm 0.02 \mathrm{a}$ & $1.22 \pm 0.01 \mathrm{a}$ \\
\hline Merlot & $24.0 \pm 0.2$ & $6.83 \pm 0.10 \mathrm{c}$ & $3.53 \pm 0.01 a$ & $0.99 \pm 0.02 b$ \\
\hline Chardonnay & $23.7 \pm 0.2$ & $8.50 \pm 0.10 a$ & $3.38 \pm 0.01 b$ & $0.98 \pm 0.02 b$ \\
\hline \multicolumn{5}{|l|}{ Vintage } \\
\hline 2007 & $25.8 \pm 0.11 \mathrm{a}$ & $8.18 \pm 0.07 a$ & $3.52 \pm 0.01 \mathrm{a}$ & $0.96 \pm 02 b$ \\
\hline 2008 & $22.9 \pm 0.14 c$ & $7.74 \pm 0.10 b$ & $3.45 \pm 0.01 b$ & $1.13 \pm 02 a$ \\
\hline 2009 & $24.1 \pm 0.15 b$ & $6.95 \pm 0.10 \mathrm{c}$ & $3.49 \pm 0.02 a b$ & $1.11 \pm 02 \mathrm{a}$ \\
\hline \multicolumn{5}{|l|}{ Signfa } \\
\hline$S \times R$ & 0.614 & 0.135 & 0.157 & 0.066 \\
\hline$Y \times S$ & 0.012 & $<0.001$ & $<0.001$ & $<0.001$ \\
\hline $\mathrm{Y} \times \mathrm{R}$ & 0.401 & 0.356 & 0.376 & $<0.001$ \\
\hline
\end{tabular}

aSignificance ( $p$ value) of scion $(S) \times$ rootstock $(R)$, year $(Y) \times S$, and $Y \times R$ interactions.

bMeans within main effects and columns having the same letters are not significantly different at $p \leq 0.05$ (Fisher LSD). 
Potassium $\left(\mathrm{K}^{+}\right)$was assessed for skin, seed, and pulp for the 2008 and 2009 vintages and is expressed on a fresh weight basis (Table 2). Only skin $\mathrm{K}^{+}$showed any significant differences due to rootstock. Across scions, 101CU and 1103P led to higher skin $\mathrm{K}^{+}$than $3309 \mathrm{C}$ and $140 \mathrm{Ru}$, but were not different from the remaining rootstocks and own-rooted vines. The differences in skin $\mathrm{K}^{+}$were quite small and were not enough to alter the total berry $\mathrm{K}^{+}$significantly. A significant scion effect was observed for each of the tissues, with $\mathrm{CH}$ having higher skin and pulp $\mathrm{K}^{+}$and total berry $\mathrm{K}^{+}$than the other scions. A significant vintage effect was observed for skin, seed, and total $\mathrm{K}^{+}$(Table 2). A significant scion $\times$rootstock interaction was observed for pulp $\mathrm{K}^{+}$(Table 2); however, the interaction was not significant $(p=0.24)$ when the data was assessed on a per berry basis. In that analysis, only SY and $\mathrm{CH}$ were affected by rootstock. For pulp and total berry $\mathrm{K}^{+}$a significant scion $\times$ vintage interaction was observed (Supplemental Table 2). SY had significantly higher pulp and total $\mathrm{K}^{+}$in 2009 , whereas $\mathrm{CH}$ had significantly higher pulp $\mathrm{K}^{+}$in 2008 but no difference in total $\mathrm{K}^{+}$. In contrast, MR had significantly higher total $\mathrm{K}^{+}$in 2009 with no difference in pulp $\mathrm{K}^{+}$.

The phenolic classes analyzed were anthocyanins and tannins from skin and seeds of MR and SY, none of which were significantly affected by rootstock across the two scion cultivars (data not shown). However, a significant scion $\times$ rootstock interaction was observed for all fruit tannin measures that were expressed on a fresh weight basis (Table 3). In contrast to seed tannin, when skin tannin was assessed on a per berry basis, the interaction was not significant $(p=0.73)$. For Merlot, $5 \mathrm{C}$ led to significantly less seed and total tannins than $101 \mathrm{CU}$, while the other rootstocks and own-rooted vines were not different. For Syrah, 101CU had significantly lower total and seed tannin (per g FW and per seed) than 1103P but was not significantly different from the other combinations. Moreover, a significant difference between scions was observed for each of the phenolic classes and the number of seeds per berry. MR had higher skin tannins, seed tannins, total tannins, and seed tannins per seed than SY, but SY had higher anthocyanins and seed number per berry. Across scions no significant vintage effect for any of the phenolic classes was observed; however, there were scion $\times$ vintage interactions for each of the phenolic classes (Supplemental Table 3). MR skin tannins were lowest in 2007 but seed tannins were highest that year, while no vintage differences were observed for SY. The yearly variation in seed tannin per seed was different for the two scions (MR: 2007>2009>2008; SY: $2009>2007 \geq 2008$ ), whereas the variation in anthocyanin content followed the same trend (MR: 2009>2007>2008; SY: $2009 \geq 2007>2008$ ).

Wine. There were some statistically significant rootstock effects on wine $\mathrm{pH}$ and $\mathrm{K}^{+}$concentrations, but $\mathrm{TA}$ and ethanol concentrations were similar among rootstocks (Table 4). Although the effects on $\mathrm{pH}$ and $\mathrm{K}^{+}$were significant, the majority of them were minor. Wines made from own-rooted vines had higher $\mathrm{pH}$ and $\mathrm{K}^{+}$; however, the difference between own-rooted and the lowest rootstock was not that different in practical terms ( $\mathrm{pH} \Delta 0.08, \mathrm{~K}^{ \pm} \Delta 41 \mathrm{mg} / \mathrm{L}$ ). Whereas the rootstock effect on $\mathrm{pH}$ was consistent across scions, significant scion $\times$ rootstock interactions were observed for wine $\mathrm{K}^{+}$and ethanol (Table 5). The rootstock did not influence $\mathrm{K}^{+}$and ethanol in $\mathrm{CH}$ wines. In contrast, MR and SY wines made from ownrooted vines had more $\mathrm{K}^{+}$than did those from grafted vines, with the exception of SY on 140Ru, which was not different from own-rooted SY. The remaining rootstock-associated differences in $\mathrm{K}^{+}$were inconsistent between these two scions. For $\mathrm{SY}$, wines made from own-rooted vines had higher ethanol

Table 2 Harvest potassium $\left(\mathrm{K}^{+}\right)$data for Syrah, Merlot, and Chardonnay grafted to various rootstocks over two vintages (2008-2009) presented by rootstock, by scion, and by vintage. Means are presented with standard error. Results are provided on fresh weight (FW) basis.

\begin{tabular}{|c|c|c|c|c|}
\hline & $\begin{array}{c}\text { Skin K }{ }^{+} \\
(\mathrm{mg} / \mathrm{g} \text { FW) }\end{array}$ & $\begin{array}{c}\text { Seed K+ } \\
\text { (mg/g FW) }\end{array}$ & $\begin{array}{c}\text { Pulp K+ } \\
\text { (mg/g FW) } \\
\end{array}$ & $\begin{array}{c}\text { Total K+ } \\
\text { (mg/g FW) }\end{array}$ \\
\hline \multicolumn{5}{|l|}{ Rootstock } \\
\hline Own-rooted & $0.53 \pm 0.03 a^{b}$ & $0.30 \pm 0.01$ & $1.40 \pm 0.03$ & $2.25 \pm 0.05$ \\
\hline $5 \mathrm{C}$ & $0.53 \pm 0.02 a b$ & $0.30 \pm 0.01$ & $1.34 \pm 0.04$ & $2.16 \pm 0.06$ \\
\hline $140 \mathrm{Ru}$ & $0.51 \pm 0.03 b$ & $0.29 \pm 0.01$ & $1.37 \pm 0.04$ & $2.17 \pm 0.06$ \\
\hline $1103 \mathrm{P}$ & $0.55 \pm 0.03 a$ & $0.31 \pm 0.01$ & $1.38 \pm 0.03$ & $2.26 \pm 0.05$ \\
\hline $3309 \mathrm{C}$ & $0.51 \pm 0.03 b$ & $0.29 \pm 0.01$ & $1.39 \pm 0.04$ & $2.18 \pm 0.06$ \\
\hline $101 \mathrm{CU}$ & $0.54 \pm 0.03 a$ & $0.29 \pm 0.01$ & $1.40 \pm 0.04$ & $2.26 \pm 0.06$ \\
\hline \multicolumn{5}{|l|}{ Scion } \\
\hline Syrah & $0.45 \pm 0.02 c$ & $0.28 \pm 0.01 b$ & $1.35 \pm 0.03 b$ & $2.08 \pm 0.05 c$ \\
\hline Merlot & $0.54 \pm 0.02 b$ & $0.34 \pm 0.01 \mathrm{a}$ & $1.36 \pm 0.02 b$ & $2.24 \pm 0.06 b$ \\
\hline Chardonnay & $0.58 \pm 0.01 \mathrm{a}$ & $0.28 \pm 0.01 b$ & $1.43 \pm 0.03 \mathrm{a}$ & $2.31 \pm 0.02 a$ \\
\hline \multicolumn{5}{|l|}{ Vintage } \\
\hline 2008 & $0.44 \pm 0.01 b$ & $0.29 \pm 0.01 b$ & $1.36 \pm 0.02$ & $2.09 \pm 0.03 b$ \\
\hline 2009 & $0.62 \pm 0.01 \mathrm{a}$ & $0.31 \pm 0.01 \mathrm{a}$ & $1.40 \pm 0.02$ & $2.33 \pm 0.02 a$ \\
\hline \multicolumn{5}{|l|}{ Signf ${ }^{a}$} \\
\hline$S \times R$ & 0.941 & 0.956 & 0.036 & 0.094 \\
\hline$Y \times S$ & $<0.001$ & 0.835 & $<0.001$ & $<0.001$ \\
\hline$Y \times R$ & 0.834 & 0.632 & 0.062 & 0.433 \\
\hline
\end{tabular}

a Significance ( $p$ value) of scion $(S) \times$ rootstock $(R)$, year $(Y) \times S$, and $Y \times R$ interactions.

${ }^{\mathrm{b}}$ Means within main effects and columns having the same letters are not significantly different at $p \leq 0.05$ (Fisher LSD). 
than wines from $140 \mathrm{Ru}, 1103 \mathrm{P}$, and $101 \mathrm{CU}$, but were the same as wines made from $5 \mathrm{C}$ and $3309 \mathrm{C}$. Nonetheless, for both $\mathrm{K}^{+}$and ethanol, the range from lowest to highest represented only a 4 to $6 \%$ difference. Significant scion effects were observed for ethanol $(\mathrm{CH}>\mathrm{SY} \geq \mathrm{MR}), \mathrm{pH}(\mathrm{SY}>\mathrm{MR}>\mathrm{CH})$, TA $(\mathrm{CH}>\mathrm{SY}>\mathrm{MR})$, and $\mathrm{K}^{+}(\mathrm{SY}>\mathrm{MR}>\mathrm{CH})$. Ethanol also varied by vintage $(2007>2009 \geq 2008)$. Significant scion $\times$ vintage interactions were observed for ethanol, $\mathrm{TA}, \mathrm{pH}$, and $\mathrm{K}^{+}$(Supple- mental Table 4). The absolute variance observed in ethanol (for all vintages and scions) was quite high $(2.7 \% \mathrm{v} / \mathrm{v})$ and the variations within each scion were consistent with the vintage effect observed for grape TSS. Annual variations in TA were inconsistent among scions (MR and SY: $2008 \geq 2009>2007$; CH: $2007>2009 \geq 2008)$. The scion $\times$ vintage interaction for pH was similar for $\mathrm{CH}$ and MR $(2007>2008 \geq 2009)$ but not SY $(2009>2007>2008)$. The $\mathrm{K}^{+}$concentration was consistent

Table 3 Anthocyanins and tannins (skin and seed) for Merlot and Syrah berries grafted to various rootstocks over three vintages (2007-2009) and two scions. Means are presented with standard error. Tannins are presented in catechin equivalents (CE). Results are provided on fresh weight (FW) basis.

\begin{tabular}{|c|c|c|c|c|c|}
\hline & $\begin{array}{l}\text { Anthocyanins } \\
\text { (mg/g FW) }\end{array}$ & $\begin{array}{l}\text { Skin tannins } \\
\text { (mg/g FW CE) }\end{array}$ & $\begin{array}{l}\text { Seed tannins } \\
\text { (mg/g FW CE) }\end{array}$ & $\begin{array}{l}\text { Total tannins } \\
\text { (mg/g FW CE) }\end{array}$ & $\begin{array}{l}\text { Seed tannins } \\
\text { (mg/seed CE) }\end{array}$ \\
\hline \multicolumn{6}{|l|}{ Merlot } \\
\hline Own-rooted & $0.81 \pm 0.06$ & $0.74 \pm 0.09 b^{b}$ & $3.40 \pm 0.22 a b$ & $4.14 \pm 0.19 a b$ & $1.97 \pm 0.15 a b$ \\
\hline $5 \mathrm{C}$ & $0.87 \pm 0.06$ & $0.88 \pm 15 a$ & $3.13 \pm 0.12 b$ & $4.01 \pm 0.17 b$ & $1.94 \pm 0.11 b$ \\
\hline 140Ru & $0.90 \pm 0.07$ & $0.86 \pm 0.11 a b$ & $3.31 \pm 0.07 a b$ & $4.16 \pm 0.14 a b$ & $1.89 \pm 0.08 b$ \\
\hline $1103 \mathrm{P}$ & $0.88 \pm 0.07$ & $0.95 \pm 0.14 a$ & $3.38 \pm 0.15 a b$ & $4.33 \pm 0.16 a$ & $1.88 \pm 0.08 b$ \\
\hline $3309 \mathrm{C}$ & $0.85 \pm 0.06$ & $0.77 \pm 0.08 b$ & $3.17 \pm 0.09 a b$ & $3.98 \pm 0.10 b$ & $1.89 \pm 0.08 b$ \\
\hline $101 \mathrm{CU}$ & $0.89 \pm 0.07$ & $0.74 \pm 0.06 b$ & $3.56 \pm 0.17 \mathrm{a}$ & $4.30 \pm 0.15 a$ & $2.13 \pm 0.14 \mathrm{a}$ \\
\hline \multicolumn{6}{|l|}{ Syrah } \\
\hline Own-rooted & $1.24 \pm 0.08$ & $0.49 \pm 0.04$ & $2.18 \pm 0.07 b c$ & $2.67 \pm 0.08 c$ & $1.45 \pm 0.15 a b$ \\
\hline $5 \mathrm{C}$ & $1.37 \pm 0.09$ & $0.49 \pm 0.03$ & $2.31 \pm 0.06 b c$ & $2.80 \pm 0.07 b$ & $1.53 \pm 0.15 a b$ \\
\hline 140Ru & $1.16 \pm 0.09$ & $0.55 \pm 0.03$ & $2.21 \pm 0.07 b c$ & $2.76 \pm 0.08 b c$ & $1.42 \pm 0.14 a b$ \\
\hline $1103 \mathrm{P}$ & $1.21 \pm 0.09$ & $0.56 \pm 0.03$ & $2.48 \pm 0.08 \mathrm{a}$ & $3.05 \pm 0.14 \mathrm{a}$ & $1.58 \pm 0.14 a b$ \\
\hline $3309 \mathrm{C}$ & $1.24 \pm 0.08$ & $0.57 \pm 0.04$ & $2.40 \pm 0.12 a b$ & $2.97 \pm 0.16 a b$ & $1.63 \pm 0.11 \mathrm{a}$ \\
\hline $101 \mathrm{CU}$ & $1.27 \pm 0.11$ & $0.52 \pm 0.02$ & $2.15 \pm 0.07 c$ & $2.67 \pm 0.07 c$ & $1.38 \pm 0.11 b$ \\
\hline \multicolumn{6}{|l|}{ Scion } \\
\hline Syrah & $1.25 \pm 0.04 \mathrm{a}$ & $0.53 \pm 0.01 b$ & $2.29 \pm 0.04 b$ & $2.81 \pm 0.04 b$ & $1.49 \pm 0.05 b$ \\
\hline Merlot & $0.87 \pm 0.03 b$ & $0.82 \pm 0.04 \mathrm{a}$ & $3.35 \pm 0.05 a$ & $4.17 \pm 0.06 \mathrm{a}$ & $1.95 \pm 0.04 \mathrm{a}$ \\
\hline \multicolumn{6}{|l|}{ Signfa } \\
\hline$S \times R$ & 0.182 & 0.035 & $<0.001$ & 0.010 & 0.010 \\
\hline$Y \times S$ & $<0.001$ & $<0.001$ & $<0.001$ & $<0.001$ & $<0.001$ \\
\hline$Y \times R$ & 0.718 & $<0.001$ & 0.289 & 0.015 & 0.173 \\
\hline
\end{tabular}

a Significance ( $p$ value) of scion $(S) \times$ rootstock $(R)$, year $(Y) \times S$, and $Y \times R$ interactions.

${ }^{b}$ Means within main effects and columns having the same letters are not significantly different at $p \leq 0.05$ (Fisher LSD).

Table 4 Wine data for Chardonnay, Merlot, and Syrah grafted to various rootstocks over three vintages (2007-2009). Measurement of potassium only 2008 and 2009. Means are presented with standard error.

\begin{tabular}{|c|c|c|c|c|}
\hline & $\begin{array}{c}\text { Ethanol } \\
\%(v / v)\end{array}$ & $\begin{array}{c}\text { TA } \\
\text { (g/L) }\end{array}$ & $\mathrm{pH}$ & $\begin{array}{c}\mathrm{K}^{+} \\
(\mathrm{mg} / \mathrm{L})\end{array}$ \\
\hline \multicolumn{5}{|l|}{ Rootstock } \\
\hline Own-rooted & $13.5 \pm 0.2$ & $5.54 \pm 0.17$ & $3.65 \pm 0.02 a^{b}$ & $920 \pm 14 a$ \\
\hline $5 \mathrm{C}$ & $13.7 \pm 0.2$ & $5.88 \pm 0.17$ & $3.60 \pm 0.02 b c$ & $879 \pm 16 c$ \\
\hline $140 \mathrm{Ru}$ & $13.6 \pm 0.2$ & $5.87 \pm 0.17$ & $3.59 \pm 0.02 b c$ & $879 \pm 19 c$ \\
\hline $1103 P$ & $13.8 \pm 0.2$ & $5.84 \pm 0.22$ & $3.61 \pm 0.02 b$ & $872 \pm 16 c$ \\
\hline $3309 C$ & $13.5 \pm 0.2$ & $5.92 \pm 0.21$ & $3.57 \pm 0.02 c$ & $886 \pm 17 b c$ \\
\hline $101 \mathrm{CU}$ & $13.6 \pm 0.2$ & $5.65 \pm 0.18$ & $3.63 \pm 0.02 a b$ & $900 \pm 17 b$ \\
\hline \multicolumn{5}{|l|}{ Scion } \\
\hline Syrah & $13.3 \pm 0.1 b$ & $5.79 \pm 0.13 b$ & $3.65 \pm 0.01 \mathrm{a}$ & $973 \pm 6.2 \mathrm{a}$ \\
\hline Merlot & $13.2 \pm 0.1 b$ & $5.08 \pm 0.12 c$ & $3.71 \pm 0.01 b$ & $916 \pm 6.7 b$ \\
\hline Chardonnay & $14.2 \pm 0.2 \mathrm{a}$ & $6.48 \pm 0.07 a$ & $3.46 \pm 0.01 c$ & $779 \pm 7.7 c$ \\
\hline \multicolumn{5}{|l|}{ Signfa } \\
\hline$S \times R$ & 0.004 & 0.240 & 0.469 & $<0.001$ \\
\hline$Y \times S$ & $<0.001$ & $<0.001$ & $<0.001$ & $<0.001$ \\
\hline $\mathrm{Y} \times \mathrm{R}$ & 0.084 & 0.861 & 0.824 & 0.974 \\
\hline
\end{tabular}

a Significance ( $p$ value) of scion $(S) \times$ rootstock $(R)$, year $(Y) \times S$, and $Y \times R$ interactions.

bMeans within main effects and columns having the same letters are not significantly different at $p \leq 0.05$ (Fisher LSD). 
between vintages for MR; however, 2009 had higher and lower potassium concentrations for $\mathrm{SY}$ and $\mathrm{CH}$, respectively, than did 2008.

In general, SY wines had higher anthocyanin concentration but lower tannins, polymeric pigments (SPP, LPP and TPP), and total iron-reactive phenolics than MR wines. A significant scion $\times$ vintage interaction was observed for each of the phenolic classes (Supplemental Table 5). In SY

Table 5 Ethanol and potassium for Chardonnay, Merlot, and Syrah grafted to various rootstocks over three (ethanol, 2007-2009) or two (potassium, 2008-2009) vintages. Means are presented with standard error.

\begin{tabular}{lcc}
\hline Chardonnay & $\begin{array}{c}\text { Ethanol } \\
\%(\mathbf{v} / \mathbf{v})\end{array}$ & $\begin{array}{c}\mathbf{K}^{+} \\
(\mathbf{m g} / \mathbf{L})\end{array}$ \\
\hline Own-rooted & $14.6 \pm 0.6$ & $784 \pm 19$ \\
$5 \mathrm{C}$ & $14.5 \pm 0.4$ & $771 \pm 17$ \\
140Ru & $14.5 \pm 0.2$ & $782 \pm 28$ \\
1103P & $14.3 \pm 0.3$ & $788 \pm 18$ \\
3309C & $14.3 \pm 0.3$ & $763 \pm 18$ \\
101CU & $14.3 \pm 0.4$ & $787 \pm 17$ \\
Merlot & & \\
Own-rooted & $13.3 \pm 0.2$ & $969 \pm 11 \mathrm{a}^{\mathrm{a}}$ \\
5C & $13.1 \pm 0.3$ & $910 \pm 11 \mathrm{~b}$ \\
140Ru & $13.3 \pm 0.2$ & $864 \pm 8.9 \mathrm{c}$ \\
1103P & $13.1 \pm 0.3$ & $893 \pm 15 \mathrm{bc}$ \\
3309C & $13.0 \pm 0.3$ & $906 \pm 13 \mathrm{~b}$ \\
101CU & $13.3 \pm 0.2$ & $950 \pm 14 \mathrm{~b}$ \\
Syrah & & \\
Own-rooted & $13.6 \pm 0.2 \mathrm{a}$ & $1009 \pm 15 \mathrm{a}$ \\
5C & $13.4 \pm 0.3 \mathrm{ab}$ & $955 \pm 12 \mathrm{c}$ \\
140Ru & $13.0 \pm 0.2 \mathrm{~b}$ & $993 \pm 17 \mathrm{ab}$ \\
1103P & $13.1 \pm 0.3 \mathrm{~b}$ & $947 \pm 15 \mathrm{C}$ \\
3309C & $13.3 \pm 0.3 \mathrm{ab}$ & $964 \pm 11 \mathrm{~b}$ \\
101CU & $13.1 \pm 0.3 \mathrm{~b}$ & $971 \pm 15 \mathrm{bc}$ \\
\hline
\end{tabular}

aMeans within main effects and columns having the same letters are not significantly different at $p \leq 0.05$ (Fisher LSD). wines, all phenolic classes varied similarly among vintages (2009>2007>2008), but not in MR wines (anthocyanins: 2009>2008>2007; tannins and total iron reactive phenolics: $2007>2008 \geq 2009$ ). Wine anthocyanins, SPP, and tannins were also affected by rootstock. Wines made from own-rooted vines had significantly higher tannin than the other wines, and own-rooted and 5C and 101CU wines also had significantly higher anthocyanins and SPP (Table 6). Although the differences were quite small ( $~ 8$ to $13 \%)$, it was decided to evaluate the basic relationship between fruit and wine anthocyanins. Using all vintages of MR and SY, a positive correlation was found $(\mathrm{r}=0.57, p<0.001)$ between fruit and wine anthocyanins, but since anthocyanins varied by scion and vintage, we decided to explore this relationship further. Correlations between fruit and wine anthocyanins across vintages were significant for both scions (Figure 1), but the relationship for MR was not as strong as that for SY. When scion was separated out on a vintage basis, SY had a significant linear relationship within each vintage, while MR was not significant for any of the vintages.

\section{Discussion}

A three-year study was conducted using three scions and five rootstocks in addition to own-rooted vines. Small-scale winemaking was conducted across the three vintages. Despite some significant differences in vine vigor, capacity, and yield (Keller et al. 2012), grafting and rootstocks caused little variation in fruit composition, which was dominated by differences among scions and vintages. In many of the measured variables, scion $\times$ vintage interactions were observed, indicating that the vintage effect varied among scions (Supplemental Tables 1, 2, 3). Scion $\times$ rootstock interactions were observed for some fruit and wine variables but tended toward small differences that would be of minor practical importance. Of the fruit variables, tannin concentrations were affected by rootstock. However, the rootstock-related variation in vine

Table 6 Wine anthocyanins, polymeric pigments (small, SPP; large, LPP; total, TPP, absorbance units, AU), tannins, and total iron reactive phenolics (IRP) data for Merlot and Syrah grafted to various rootstocks over three vintages (2007-2009). Means are presented with standard error. Tannins are presented in catechin equivalents (CE).

\begin{tabular}{|c|c|c|c|c|c|c|}
\hline & $\begin{array}{l}\text { Anthocyanins } \\
(\mathrm{mg} / \mathrm{L})\end{array}$ & $\begin{array}{l}\text { SPP } \\
\text { (AU) }\end{array}$ & $\begin{array}{l}\text { LPP } \\
\text { (AU) }\end{array}$ & $\begin{array}{l}\text { TPP } \\
\text { (AU) }\end{array}$ & $\begin{array}{c}\text { Tannins } \\
\text { (mg/L CE) }\end{array}$ & $\begin{array}{l}\text { Total IRP } \\
\text { (mg/L CE) }\end{array}$ \\
\hline \multicolumn{7}{|l|}{ Rootstock } \\
\hline Own-rooted & $726 \pm 22 a^{b}$ & $0.73 \pm 0.04 a$ & $0.48 \pm 0.04$ & $1.14 \pm 0.04$ & $370 \pm 14 a$ & $1045 \pm 32$ \\
\hline $5 \mathrm{C}$ & $740 \pm 17 a$ & $0.67 \pm 0.03 b$ & $0.44 \pm 0.02$ & $1.11 \pm 0.05$ & $339 \pm 22 b$ & $1014 \pm 38$ \\
\hline $140 \mathrm{Ru}$ & $646 \pm 19 b$ & $0.63 \pm 0.02 b$ & $0.47 \pm 0.04$ & $1.11 \pm 0.07$ & $335 \pm 17 b$ & $979 \pm 39$ \\
\hline $1103 \mathrm{P}$ & $678 \pm 17 b$ & $0.67 \pm 0.03 b$ & $0.47 \pm 0.07$ & $1.06 \pm 0.04$ & $316 \pm 24 b$ & $982 \pm 47$ \\
\hline $3309 \mathrm{C}$ & $662 \pm 17 b$ & $0.62 \pm 0.03 b$ & $0.46 \pm 0.06$ & $1.08 \pm 0.07$ & $329 \pm 20 b$ & $1008 \pm 42$ \\
\hline $101 \mathrm{CU}$ & $738 \pm 24 a$ & $0.70 \pm 0.03 a$ & $0.39 \pm 0.03$ & $1.18 \pm 0.06$ & $334 \pm 18 b$ & $1014 \pm 36$ \\
\hline \multicolumn{7}{|l|}{ Scion } \\
\hline Syrah & $767 \pm 11 \mathrm{a}$ & $0.61 \pm 0.01 b$ & $0.34 \pm 0.04 b$ & $0.96 \pm 0.02 b$ & $304 \pm 11 b$ & $913 \pm 20 b$ \\
\hline Merlot & $631 \pm 10 b$ & $0.73 \pm 0.02 a$ & $0.55 \pm 0.04 a$ & $1.28 \pm 0.03 a$ & $371 \pm 9 a$ & $1102 \pm 20 a$ \\
\hline \multicolumn{7}{|l|}{ Signfa } \\
\hline$S \times R$ & 0.157 & 0.322 & 0.184 & 0.559 & 0.745 & 0.596 \\
\hline$Y \times S$ & $<0.001$ & 0.676 & 0.213 & 0.159 & $<0.001$ & $<0.001$ \\
\hline$Y \times R$ & $<0.001$ & 0.271 & 0.176 & 0.111 & 0.003 & 0.099 \\
\hline
\end{tabular}

asignificance ( $p$ value) of scion $(S) \times$ rootstock $(R)$, year $(Y) \times S$, and $Y \times R$ interactions.

${ }^{\mathrm{b}}$ Means within main effects and columns having the sameletters are not significantly different at $p \leq 0.05$ (Fisher LSD). 


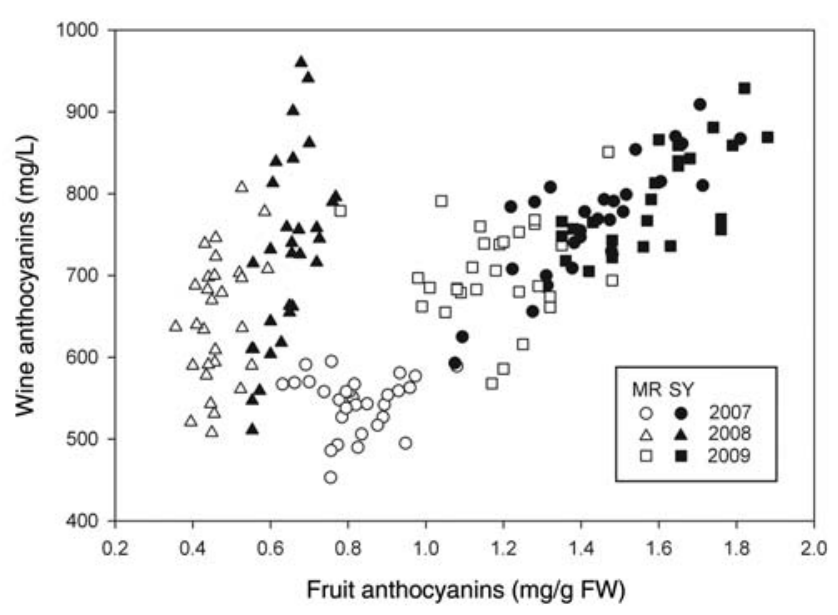

Figure 1 Relationship between fruit and wine anthocyanins for Merlot (MR) and Syrah (SY) over three vintages. Correlations by scion: MR $r=$ $0.27, p<0.02$; SY $r=0.53, p<0.001$. Correlations by vintage for Merlot: $2007 \mathrm{r}=0.93, p<0.001 ; 2008, \mathrm{r}=0.56, p<0.001 ; 2009 \mathrm{r}=0.73, p<$ 0.001 . Correlations by vintage for Syrah: $2007 r=0.82, p<0.001 ; 2008$ $r=0.61, p<0.001 ; 2009 r=0.72, p<0.001$.

growth and yield components (Keller et al. 2012) was unable to explain these differences. Moreover, the effect on skin tannins was negated on a per berry basis, suggesting that the variation in berry weight obscured any rootstock effect. For seed tannins, the rootstock effect represented at most a $12 \%$ difference in terms of average concentration (Table 4), so its practical significance is dubious. Scion $\times$ rootstock interactions were observed in the wine for $\mathrm{K}^{+}$and ethanol. Chardonnay proved to be rather unresponsive to rootstocks, whereas in the red wines grafting tended to be associated with lower $\mathrm{K}^{+}$(MR and SY) and ethanol (SY only). The rootstock-induced differences in $\mathrm{K}^{+}$were paralleled by similar differences in wine $\mathrm{pH}$, tending toward slightly lower values in wines from grafted vines.

The rootstock effect on wine $\mathrm{pH}$ reflected that on fruit $\mathrm{pH}$, but the same was not true for $\mathrm{K}^{+}$. Across all vintages own-rooted fruit had the highest $\mathrm{pH}$, although this is somewhat deceiving because the greatest difference in $\mathrm{pH}$ units was $\sim 0.09$. It is understood that $\mathrm{Na}^{+}$and $\mathrm{K}^{+}$are exchanged for $\mathrm{H}^{+}$during grape ripening via transport proteins and this exchange is thought to be analogous to a titration of protons by a strong base (Boulton 1980). As indicated in the introduction, multiple studies have observed that vines grafted to Ramsey, 1103P, 140Ru, and 101-14 Mgt for both Chardonnay and Syrah have consistently higher concentrations of $\mathrm{K}^{+}$in the fruit and wine. In this study, we evaluated each tissue separately and found no differences in the pulp, seed, or total berry $\mathrm{K}^{+}$. However, some minor differences were observed in skin $\mathrm{K}^{+}$, with both $1103 \mathrm{P}$ and $101 \mathrm{CU}$ having greater concentrations than $3309 \mathrm{C}$ and $140 \mathrm{Ru}$, while own-rooted and $5 \mathrm{C}$ were not different (Table 2). The wine $\mathrm{K}^{+}$concentrations were consistent with these observations, with some minor significant differences representing $\sim 4$ to $6 \%$ of the wine $\mathrm{K}^{+}$ concentration. Again, this variation could not be explained by rootstock-induced differences in vine growth and yield formation (Keller et al. 2012), and by any practical assess- ment neither fruit nor wine $\mathrm{K}^{+}$was changed by grafting in this experiment. It is unclear why our results are different than results from studies in Australia.

In previous work, only wine color measures were taken as an assessment of the effect of grafting on phenolic composition. In this work, berry anthocyanins, skin tannins, and seed tannins were measured, none of which were affected by grafting. However, anthocyanins were somewhat ( $\sim 8$ to $13 \%$ ) higher in wines made with fruit from own-rooted vines and vines grafted to $101 \mathrm{CU}$ and $5 \mathrm{C}$ compared with wines made from other rootstocks. Our evaluation of the relationship between fruit and wine anthocyanins revealed that anthocyanin extractability was unlikely to be influenced by rootstock. The present work suggests that the relationship between fruit and wine color is dependent on cultivar and vintage: while a fairly strong, but variable, relationship may exist for some $V$. vinifera cultivars (e.g., Syrah), that does not seem to be true for others (e.g., Merlot). This result is consistent with recent research conducted in Australia (Ristic et al. 2010), which found a significant relationship between grape and wine anthocyanin concentration for two vintages of Syrah. It is unclear whether the apparent vintage effects and the differences among cultivars in our work are due to differences in skin anthocyanin profiles or other underlying factors.

The relationship between fruit and wine anthocyanin is considered tenuous because of the conversion of anthocyanins into polymeric pigments by reacting with other phenolics and organic acids upon crushing of the fruit (Somers 1971, Remy et al. 2000, Bakker and Timberlake 1997). Because of this conversion it is important to distinguish the timing of the wine anthocyanin measurement, and in this case we evaluated the wine at press (7 days), which is quite early during wine color evolution. Previous studies have shown only small amounts of polymeric pigment formation during the first 10 days of fermentation in Pinot noir (Gao et al. 1997). In the present study, SY, which had more fruit and wine anthocyanins and less polymeric pigments (SPP, LPP, and TPP) than MR, had linear fruit and wine anthocyanin relationships that were dependent on vintage. By contrast, MR, which had more wine tannins and polymeric pigments $(16 \%$ higher SPP, $39 \%$ higher LPP, $25 \%$ higher TPP) than SY, had poor fruit and wine anthocyanin relationships, suggesting that greater formation of polymeric pigments in MR may be clouding the relationship of fruit and wine anthocyanins. Thus, the amount of tannin may alter the relationship between fruit and wine anthocyanins. This suggestion is somewhat contradictory to observations by Ristic et al. (2010), who found that the relationship between fruit and wine anthocyanins improved after 12 months of wine aging. However, their study was limited to SY and two vintages. It is unclear whether the unique relationship in 2008 (Figure 1) was associated with the high crop yields that year (Keller et al. 2012). More research is necessary to clarify these findings.

The influence of rootstock on fruit tannins (skins, seeds, total) depended on the scion: whereas few and minor differences were found in MR, 1103P tended to increase tannins in SY and $101 \mathrm{CU}$ tended to decrease them, especially in the 
seeds. Nonetheless, the wines from own-rooted vines of both scions had 8 to $15 \%$ higher tannin concentrations than the wines from grafted vines. Although overall MR fruit and wines had higher tannin concentrations than SY, the relationship between fruit and wine tannins was not significant. Experiments have shown that only a portion of skin ( 40 to $50 \%)$ and seed ( 16 to $44 \%)$ tannin is extracted into the wine (Adams and Scholz 2008, Harbertson et al. 2009). Moreover, skin and seed tannins are extracted at different rates (Pastor del Rio and Kennedy 2006) and in different proportions depending on winemaking technique (Cerpa-Calderon and Kennedy 2008, Harbertson et al. 2009). Skin tannins might be expected to show a better relationship with wine tannins because our experiment had a 7-day maceration period and skin tannins are extracted quickly (similar to anthocyanins reaching a maximum at 5 days), while seed tannins are extracted more slowly (Pastor del Rio and Kennedy 2006). However, neither skin nor seed tannins showed a significant correlation with wine tannins between and within vintages, and this lack of relationship was unaffected by rootstock. This finding is consistent with previous research, which has suggested that there is a general "problem of extraction" with tannins, whereby cell wall material from the skin and mesocarp are binding significant amounts of the skin and seed tannins (Adams and Scholz 2008). Our data demonstrate that both cultivar and vintage are dominant variables in the problem of extraction. The observed vintage effect varied by scion (e.g., highest MR wine tannin in 2007, but highest SY wine tannin in 2009) and was unrelated to plant water status, seasonal temperature variation, or differences in vine growth and yield (Keller et al. 2012). Previous research has shown that changes in skin tannin structure during ripening modify the interaction of tannins with cell wall material (Bindon and Kennedy 2011), although the data were collected from one growing season only, so it is unclear whether changes in tannin structure are affected by vintage. Ristic et al. (2010) reported a significant relationship between skin and wine tannins but a negative relationship between seed and wine tannins; clearly more research is necessary to determine what is causing this variation.

\section{Conclusion}

In this three-year evaluation of the effect of rootstock on grape and wine composition, we compared fruit and wine from own-rooted and grafted vines (1103P, 140Ru, 3309C, $5 \mathrm{C}$, and 101CU) using three scions (Chardonnay, Merlot, and Syrah) under conditions of deficit irrigation. The evaluation included basic grape and wine components (TSS, pH, TA, $\mathrm{K}^{+}$, and ethanol) and variables important to red wine quality (anthocyanins, tannins, and polymeric pigments). Results showed that rootstock caused few significant differences in fruit and wine composition, and instead the dominant variables were scion and, to a lesser extent, vintage. All fruit and wine variables measured, with the exception of TSS, varied significantly with scion. Only TSS and berry size were consistently affected by vintage. Rootstock had only minor effects on grape anthocyanins and tannins, but some small effects were observed for wine anthocyanins and tannins. The relationship between fruit and wine anthocyanins was found to depend on scion and vintage and was unaffected by rootstock. No significant relationship was found between fruit and wine tannins.

\section{Literature Cited}

Adams, D.O., and R.C. Scholz. 2008. Tannins-the problem of extraction. In Proceedings of the Thirteenth Australian Wine Industry Technical Conference. R. Blair et al. (eds.), pp. 160-164. AWITC, Glen Osmond, South Australia.

Bakker, J., and C.F. Timberlake. 1997. Isolation, identification, and characterization of new color-stable anthocyanins occurring in some red wines. J. Agric. Food Chem. 45:35-42.

Bindon, K.A., and J.A. Kennedy. 2010. Ripening-induced changes in grape skin proanthocyanidins modify their interaction with cell walls. J. Agric. Food Chem. 59:2696-2707.

Boulton, R. 1980. The general relationship between potassium, sodium and $\mathrm{pH}$ in grape juice and wine. Am. J. Enol. Vitic. 31:182-186.

Cerpa-Calderon, F.K., and J.A. Kennedy. 2008. Berry integrity and extraction of skin and seed proanthocyanidins during red wine fermentation. J. Agric. Food Chem. 56:9006-9014.

Gao, L., B. Girard, G. Mazza, and A.G. Reynolds. 1997. Changes in anthocyanins and color characteristics of Pinot noir wines during vinification processes. J. Agric. Food Chem. 45:2003-2008.

Gholami, M., Y. Hayasaka, B.G. Coombe, J.F. Jackson, S.P. Robinsoni, and P.J. Williams. 1995. Biosynthesis of flavour compounds in Muscat Gordo Blanco grape berries. Aust. J. Grape Wine Res. 1:19-24.

Gong, H., D.H. Blackmore, and R.R. Walker. 2010. Organic and inorganic anions in Shiraz and Chardonnay grape berries and wine as affected by rootstock under saline conditions. Aust. J. Grape Wine Res. 16:227-236.

Harbertson, J.F., and E.D. Harwood. 2009. Partitioning of potassium during commercial scale red wine fermentations and model wine extractions. Am. J. Enol. Vitic. 60:43-49.

Harbertson, J.F., J.A. Kennedy, and D.O. Adams. 2002. Tannin in skins and seeds of Cabernet Sauvignon, Syrah, and Pinot noir berries during ripening. Am. J. Enol. Vitic. 53:54-59.

Harbertson, J.F., E.A. Picciotto, and D.O. Adams. 2003. Measurement of polymeric pigments in grape berry extracts and wines using a protein precipitation assay combined with bisulfite bleaching. Am. J. Enol. Vitic. 54:301-306.

Heredia, T.M., D.O. Adams, K.C. Fields, P.G. Held, and J.F. Harbertson. 2006. Evaluation of a comprehensive red wine phenolics assay using a microplate reader. Am. J. Enol. Vitic. 57:497-502.

Iland, P., N. Bruer, G. Edwards, S. Weeks, and E. Wilkes. 2004. Chemical Analysis of Grapes and Wine: Techniques and Concepts. Patrick Iland Wine Promotions, Campbelltown, Australia.

Keller, M. 2010. The Science of Grapevines: Anatomy and Physiology. Academic Press, Burlington, MA.

Keller, M., L.J. Mills, and J.F. Harbertson. 2012. Rootstock effects on deficit-irrigated winegrapes in a dry climate: Vigor, yield formation, and fruit ripening. Am. J. Enol. Vitic. 63:29-39.

Pastor del Rio, J.L., and J.A. Kennedy. 2006. Development of proanthocyanidins in Vitis vinifera L. cv. Pinot noir grapes and extraction into wine. Am. J. Enol. Vitic. 57:125-132.

Picciotto, E.A. 2002. An investigation of polymeric pigments in red wine by means of a biochemical assay and synthesis. M.S. thesis, University of California, Davis.

Rebelein, H.,1973. Rapid method for the determination of the alcohol, sugar and total $\mathrm{SO}_{2}$ contents (by distillation) in wine and fruit juices 
and also for determining blood alcohol. Chem. Mikrobiol. Technol. Lebensm. 2:112-121.

Remy, S., H. Fulcrand, B. Labarbe, V. Cheynier, and M. Moutounet. 2000. First confirmation in red wine of products resulting from direct anthocyanin-tannin reactions. J. Sci. Food Agric.80:745-751.

Ristic, R., K. Bindon, L.I. Francis, M.J. Herderich, and P.G. Iland. 2010. Flavonoids and $\mathrm{C}_{13}$-norisoprenoids in Vitis vinifera $\mathrm{L}$. cv. Shiraz: Relationships between grape and wine composition, wine colour and wine sensory properties. Aust. J. Grape Wine Res. 16:369-388.

Somers, T.C. 1971. The polymeric nature of wine pigments. Phytochemistry 10:2175-2186.

Walker, R.R., P.R. Clingeleffer, G.H. Kerridge, E.H. Ruhl, P.R. Nicholas, and D.H. Blackmore. 1998. Effects of the rootstock Ramsey
(Vitis champini) on ion and organic acid composition of grapes and wine, and on wine spectral characteristics. Aust. J. Grape Wine Res. 4:100-110.

Walker, R.R., P.E. Read, and D.H. Blackmore. 2000. Rootstock and salinity effects on rates of berry maturation, ion accumulation and colour development in Shiraz grapes. Aust. J. Grape Wine Res. 6:227-239.

Walker, R.R., D.H. Blackmore, and P.R. Clingeleffer. 2010. Impact of rootstock on yield and ion concentrations in petioles, juice and wine of Shiraz and Chardonnay in different viticultural environments with different irrigation water salinity. Aust. J. Grape Wine Res. 16:243-257. 